presented a highly competent and scholarly review of blood groups in cattle. In one cattle system, $J$, the antigenic substance is found in soluble form in various body fluids and tissues, and is absorbed on the red cells. This was the subject of a contribution by Dr. W. H. Stone (University of Wisconsin, Madison), who discussed physiological, genetical and chemical aspects. Dr. J. Gasparski (Polish Academy of Science) was unfortunately unable to attend the meeting, and his paper-on red cell antigens of the European bison identified by cattle blood typing reagents - was read for him. A definitive account of blood-group systems of sheep was given by Dr. B. A. Rasmusen (University of Illinois, Urbana), and the meeting concluded with a fascinating account, presented by Dr. A. Eyquem (Pasteur Institute, Paris), of blood group investigations by himself and Drs. L. Podliachouk and P. Millot. Species involved were chimpanzees, horses, mules, donkeys, sheep, pigs and cattle.
The papers described above are to be published as soon as possible in the Annals of the New York Academy of Sciences, and should remain definitive for some time to come. In addition, the meeting provided an excellent opportunity for exchange of opinions between workers in widely diverse fields, and there can have been few attending who did not acquire ideas for new approaches. Discussions were especially enlivened by the presence of some guests noted particularly for their research on human blood groinps, among whom may be especially mentioned Drs. W. C. Boyd, S. D. Lawler, P. A. Levine and A. S. Wiener. Other activities associated with the meeting included an evening discussion meeting, which resolved to form an Immunogenetics Society of America, another evening discussion on blood-group nomenclature, and a most enjoyable dinner in honour of Dr. M. R. Irwin, arranged by some of his past students.

D. G. Gilmour

\title{
DESIGN AND USE OF RESPIRATORS
}

A

JOINT meeting of the Ergonomies Research Society and the British Occupational Hygiene Society at Porton on July 5 and 6 was devoted to the study of respirators. The Societies were welcomed by Dr. E. A. Perren, director of the Chemical Defence Experimental Establishment (C.D.E.E.). The first paper, by C. G. Trotman (C.D.E.E.), dealt with the history of the subject. Dust masks were much the oldest form of respirator but were not really significant until a performance standard for industrial dusts was established in 1933. Canister respirators for protection against industrial gases grew from the chlorine box respirator of the First World War. The Chemical Works Regulations of 1922 enforced the provision of respirators of an adequate standard; since then, systems of coding and testing respirators for practically all known industrial and agricultural hazards have been laid down.

R. G. Dorman (C.D.E.E.) discussed fibrous filters for protection against aerosol particles. Sizes near $0 \cdot 3 \mu$ diameter are the most difficult to filter; collisions with filter fibres are less probable for particles having low inertia and small Brownian motion so that they tend to penetrate the filter relatively easily. Experimental demonstration of a minimum of filtration efficiency at a certain particle size proved the general validity of the theory of filter action. The resin-wool filter was described, which combined extremely low air-flow resistance with high efficiency, due to electrostatic action. Methylene blue and sodium aerosol testing, with flame photometer detection, were also discussed, and desirable standards of protection indicated.

F. A. P. Maggs (C.D.E.E.) gave an account of the removal of gases by activated charcoal. Adsorption is a matter of the surface area of the charcoal and the number of molecules of gas, so that a high molecular-weight gas is retained better than one having small molecules. The life-time of a respirator against volatile, low-molecular-weight vapours may be quite short and there is some difficulty about giving proper warning of incipient failure to the user.

J. E. Cotes (Medical Research Council Pneumoconiosis Research Unit) dealt with physiological aspects of respirator design, including breathing apparatus supplied with oxygen. Factors of impor- tance included dead space, flow-resistance, vision, fit of face-piece, and leakage. In addition to protecting the wearer, breathing sets with closed circuit made it possible to help him in situations involving physiological stress by humidifying, cooling and adding oxygen to the air which he breathed.

The ergonomics of the respirator was dealt with by R. J. Shephard (C.D.E.E.), who described methods of assessing the loss of performance resulting from wearing respirators. Deterioration of specific functions was slight, and the expenditure of energy occasioned by dead space and resistance only amounted to a few per cent of maximum effort under average conditions. General discomfort, sweating and unusual activity, however, reduced tolerance unless the subject were adequately motivated.

The work of ventilation was analysed by $\mathrm{E}$. A. Cooper (Department of Anæsthesia, Newcastle upon Tyne), who directed attention to the contrasting resistance laws which were relevant to laminar flow in filter beds and turbulent flow in pipes and valves; the latter rises much more rapidly with an increase in the velocity of breathing. By considering the mechanism of respiration and cardiorespiratory function it was possible to lay down allowable standards of resistance.

Respirators, besides being protective devices, have been used in physiological research since the days of Lavnisier. H. S. Wolff (Medical Research Council, Hampstead) dealt with such applications. Mouthpieces were often used in place of masks, for brief experiments, but were uncomfortable and promoted salivation. Masks were important for measuring expenditure of energy from consumption of oxygen; types produced for anæsthetics, for airmen and for gas-masks were commonly adapted for physiological research, and various measuring devices could be attached to them.

Communication between persons wearing breathing equipment was the subject of a paper by J. Ernsting and J. E. Gabb (Royal Air Force Institute of Aviation Medicine). The situation is complicated in aircraft by the effects of reduced pressure on auditory acuity. Speech gives rise to respiratory flow patterns which impose a severe strain on the flow capacity of respiratory equipment. 
J. R. Carr (Royal Navy) spoke of the design of underwater breathing apparatus. The lungs of the user must be pressurized to the equivalent of the surrounding water, which results in a rapid increase with depth of the mass of gas consumed. Long endurance therefore necessitates either re-breathing or a surface supply of gas. Gases under pressure may affect man adversely, and psychological and physiological hazards may be introduced by limitations of the breathing set.

F. Lavenne and P. Leyh (Institut d'Hygiene des Mines, Hasselt, Belgium) compared the performance of two closed-circuit breathing sets, one working with compressed oxygen and the other with liquid air, and an open-circuit apparatus supplied with compressed air. Exercises performed at different temperatures showed that the inspired air temperature depended mainly on release of heat by absorption of carbon dioxide and was lowest in the open circuit apparatus. Light weight was an important point.

Industrial gas and dust masks were analysed by H. J. R. Letts (C.D.E.E.), who emphasized the influence on design of legislation requiring approved types. Dangers due to limitations of the absorbing medium are not serious, but the risk from leakage at the face-piece is significant and difficult to measure; a 10 per cent leakage due to physical activity was common, and wearability of a mask was an important attribute because of the user's tendency to avoid discomfort by discarding it. Leakage through the face-piece seems to be a fundamental limitation of the container respirator and may have to be avoided by electrically driven individual fan units.

The iron and steel industry uses respirators to a large extent, as was explained by J. Graham Jones
(Richard Thomas and Baldwin, Ltd.). Major problems were carbon monoxide, from blast furnaces, and dust. For the former, only air-line masks had been successful, and compressed-air points were provided on furnace platforms. In the Fire Service, F. C. S. Shirling (Home Office) stated that respirators were useless, because of oxygen deficiency, and self-contained breathing sets were used which had a useful life up to $1 \mathrm{hr}$. An overriding factor in design was the necessity for instant availability.

The final session was conducted with Mr. A. C. Peacock (formerly of C.D.E.E.) in the chair, who also read a paper on the manufacture and testing of respirators. He suggested that it would be advantageous if users were to collaborate in producing a limited number of designs, which should be manufactured by a single organization.

S. T. Hermiston, R. F. Hounam and R. P. Rowlands (United Kingdom Atomic Energy Authority) listed the various types of apparatus for protecting people who handled radioactive substances. The problems encountered in other applications are here augmented by the necessity of decontaminating the appliances after use. For this reason, a worker is issued with a respirator from a pool instead of its being fitted to him individually, a practice which drew some criticisms.

The final application of respiratory devices discussed was the important one of mine rescue, by C. R. Senneck (Safety in Mines Research Establishment). A new closed-circuit liquid-oxygen sot has outstanding performance; it weighs $33 \mathrm{lb}$. fully charged and gives cool dry air for more than $2 \mathrm{hr}$. During heavy work at $90^{\circ} \mathrm{F}$., respiratory cooling of more than $1 \mathrm{kcal} . / \mathrm{min}$. is available and the resistance is only $1 \mathrm{~cm}$. water at $3001 . / \mathrm{min}$.; operation is automatic. C. N. DAvies

\section{FOUR DECADES OF STATE FORESTRY IN GREAT BRITAIN}

\begin{abstract}
$\mathrm{T}$ HE publication of the forty-first annual report of the Forestry Commission in Great Britain for the year ended September 30, 1960,* marks the first year of State forestry activity in its fifth decade of existence. In temperate countries it takes more than four decades to create new forests, a process which does not end with the planting of so many trees on so many acres. In the year $1959 / 60$ the State planted 61,700 acres and private enterprise 36,900 acres, making a total of 98,600 acres. If this rate continues and if we assume that the average length of rotation, making allowance for the slow growth to be expected on much of the land being planted, is 80 years, then it would seem that the final wooded area will, in that time, amount to $8,000,000$ acres plus $2,000,000$ acres already existing, or $10,000,000$ acres in all. If this is the avowed objective, the position at the moment is reasonably good. The competition for land in Great Britain has not prevented the Forestry Commission from adding during the year some 60,000 acres of plantable land to bring its total holding thereof to $1,618,400$ acres. In describing the year's work it is interesting
\end{abstract}

- Forestry Commission. Forty-first Annual Report of the Forestry Commissioners for the Year ended 30th September, 1960. Pp. 69+ 9 plates. (London: H.M. Stationery Office, 1961.) 58. net. to find, however, that private forestry is placed before State forestry. This may be merely politeness, but things have certainly moved a long way since the last chairman expressed the view that private enterprise in forestry was doomed. It has greatly strengthened its position in recent years and the policy of paying grants in aid to the tune of $£ 1,150,000$ a year has given it a remarkable boost. The dedication of woodlands to productive forestry has advanced to the extent that the area of private woodlands eligible, or about to become eligible, for State aid is now 837,476 acres. There is thus quite a healthy balance between the managed woodlands of the State and those of the private owner. It is surely time to abolish, if possible, the needless complication of having two bases of dedication, for only two of the 562 schemes in operation are on basis II.

The report introduces to the public the concept of the 'working-plan', which is, in fact, a plan of management for the forest. It is defined as being "in effect, a blueprint for a forest or group of forests" and " $\mathrm{a}$ direction to succeeding generations of foresters ensuring that in all stages of development the basic objectives are kept clearly in mind". One might ask what is a blueprint? Have British foresters become that mechanically minded? In 1960 a new 